\title{
Adaptabilidade e estabilidade de clones de cana-de-açúcar
}

Antonio Ribeiro Fernandes Júnior (1,2*); João Antonio da Costa Andrade ('); Pedro César dos Santos ('); Hermann Paulo Hoffmann ( $\left.{ }^{3}\right)$; Roberto Giacomini Chapola ( $\left.{ }^{4}\right)$; Monalisa Sampaio Carneiro (3); Danilo Eduardo Cursi ( $\left.{ }^{4}\right)$

\author{
(') Universidade Estadual Paulista "Júlio de Mesquita Filho" (UNESP), Programa de Pós-Graduação em Agronomia - Sistemas de \\ Produção, 15385-000 llha Solteira (SP), Brasil. \\ (2) Universidade Federal de São Carlos (UFSCar), Programa de Melhoramento Genético da Cana-de-açúcar (PMGCA), Estação \\ Experimental de Valparaíso, 16880-000 Valparaíso (SP), Brasil. \\ (3) UFSCar, Departamento de Biotecnologia e Produção Vegetal e Animal, 13604-900 Araras (SP), Brasil. \\ (4) UFSCar, PMGCA, Centro de Ciências Agrárias, 13604-900 Araras (SP), Brasil. \\ $\left({ }^{*}\right)$ Autor correspondente: antonio@cca.ufscar.br
}

Recebido: 2/jan./2013; Aceito: 26/jul./2013

\section{Resumo}

O objetivo deste trabalho foi identificar clones de cana-de-açúcar produtivos, com boa estabilidade e adaptabilidade no estado de São Paulo e, também, identificar locais mais representativos para seleção e experimentação. Foram avaliados dez clones e duas testemunhas comerciais de maturação média-tardia em primeira soca de experimentos colhidos em agosto de 2009 , utilizando o método de regressão bissegmentada e análise AMMI (Additive Main Effects and Multiplicative Interaction Analysis). Os resultados dos dois métodos foram comparados e evidenciaram que os clones RB975201, RB975157, RB975932, RB975242 e RB975162 foram os mais promissores devido à produtividade superior à das testemunhas, a alta estabilidade verificada em um ou nos dois métodos e a adaptabilidade ampla ou específica. O ambiente Tarumã apresentou maior estabilidade e capacidade de discriminação entre os genótipos, o que permite um ordenamento mais confiável em relação à média geral dos ambientes testados.

Palavras-chave: Saccharum spp., interação genótipo x ambiente, regressão bissegmentada, AMMI.

\section{Adaptability and stability of sugarcane clones}

\begin{abstract}
The objective of this study was to identify clones of sugarcane with good stability and adaptability in the State of São Paulo, Brazil, and also identifying locations most representative for selection and experimentation. Ten clones and two commercial checks of medium-late maturation were evaluated in the first-ratoon of experiments harvested in August 2009, using bissegmented regression and AMMI (Additive Main Effects and Multiplicative Interaction Analysis) methods. The results of two methods were compared and they evidenced that the clones RB975201, RB975157, RB975932, RB975242 and RB975162 are the most promising, showing higher production when compared to the checks, higher stability observed in one or both statistical methods and broader or more specific adaptability. The environment Tarumã presented higher stability and capacity to discriminate genotypes, allowing an ordering more reliable as compared to the overall mean of the environments tested.
\end{abstract}

Key words: Saccharum spp., genotype x environment interaction, bissegmented regression, AMMI.

\section{INTRODUÇÃO}

A cultura da cana-de-açúcar (Saccharum spp.) destinada ao setor sucroenergético, no Brasil, superou a área de 8,5 milhóes de hectares em produção na safra 2012/13, tendo São Paulo como o principal estado produtor, com mais de 51\% da produção do país (ConAB, 2012).

Um dos objetivos dos programas de melhoramento genético da cana-de-açúcar é a liberação de clones adaptados às diversas condições edafoclimáticas
(Hoffmann et al., 1999). Para isso foi preciso realizar diversos ensaios em campo com clones promissores, sendo possível identificar a interação genótipo com ambiente $(\mathrm{G} \times \mathrm{A})$ e efetuar análises de adaptabilidade e estabilidade fenotípica, o que permitiu recomendar genótipos com maior previsibilidade de produção (Vencovsky, 1986). Nesse contexto, uma das estratégias para minimizar o efeito da interação $\mathrm{G} \times \mathrm{A}$ é a identificação de genótipos com maior estabilidade fenotípica (Oliveira, 2004). 
Diversos autores desenvolveram conceitos e índices, sugerindo métodos para a avaliação da estabilidade fenotípica em plantas. O conceito de adaptabilidade para fins agrícolas refere-se à resposta produtiva do genótipo à melhoria ambiental e o conceito mais aceito de estabilidade refere-se à previsibilidade dessa resposta às variaçôes ambientais. Os métodos que melhor avaliam esses fenômenos são aqueles baseados na regressão da produtividade de cada genótipo em função de um índice para cada ambiente, calculado pela diferença entre a média do ambiente, considerando todos os genótipos, e a média geral de todos os genótipos em todos os ambientes. Portanto, os parâmetros básicos para medir-se a adaptabilidade e a estabilidade de um genótipo são, respectivamente, o coeficiente de regressáo e os desvios dessa regressão (Eberhart e Russel, 1966; Finlay e Wilkinson, 1963). Silva e Barreto (1986) propuseram uma alteração em que esses parâmetros são estimados pelo ajuste de uma única equação, representada por uma reta bissegmentada, sendo os genótipos avaliados separadamente em ambientes desfavoráveis e favoráveis. Cruz et al. (1989) propuseram uma extensão desse método, adequando-o aos propósitos do melhoramento. Na regressão bissegmentada, o genótipo ideal deve apresentar alta produtividade, coeficiente de regressão menor do que um nos ambientes desfavoráveis e maior do que um nos ambientes favoráveis, além de desvios de regressão não significativos (BorÉm e Miranda, 2005). Segundo Vencovsky e Barriga (1992), deve-se preferir a utilização dos modelos bissegmentados em relação aos modelos lineares simples quando os estudos envolvem um número elevado de ambientes.

Um método de aplicação mais recente no Brasil é a chamada análise AMMI (Additive Main Effects and Multiplicative Interaction Analysis). Nesse caso é utilizado um modelo de efeitos principais aditivos e interação multiplicativa. Esse método combina técnicas estatísticas de análise de variância e componentes principais para ajustar, respectivamente, os efeitos principais (genótipos e ambientes) e os efeitos da interação G×A (Zobel et al., 1988). A análise AMMI pode ajudar tanto na identificaçáo de genótipos de alta produtividade e largamente adaptados como na realização do chamado zoneamento agronômico com fins de recomendação regionalizada e de seleção de locais de teste (Gauch e Zobel, 1996).

Diante da diversidade de modelos para estudo da interação G×A e da importância desse fenômeno para a cultura, neste trabalho foram utilizados os métodos de regressão bissegmentada propostos por CRUZ et al. (1989) e o AMMI (ZoBel et al., 1988) para identificar clones de cana-de-açúcar produtivos, com boa estabilidade e adaptabilidade no estado de São Paulo e, também, para identificar locais mais representativos para seleção e experimentação.

\section{MATERIAL E MÉTODOS}

Os experimentos foram instalados em dez unidades produtoras de cana-de-açúcar no estado de São Paulo (Tabela 1; Figura 1), avaliando-se os clones RB975033 (C1), RB975039 (C2), RB975086 (C3), RB975157 (C4), RB975162 (C5), RB975184 (C6), RB975201 (C7), RB975242 (C8), RB975270 (C9), RB975932 (C10) e as testemunhas comerciais RB867515 (C11) e SP81-3250 (C12). Os clones RB são provenientes de hibridação ocorrida no ano de 1997, com características de maturação média-tardia, destaques na fase anterior do melhoramento (fase T3). As testemunhas RB867515 e SP81-3250 são os genótipos mais

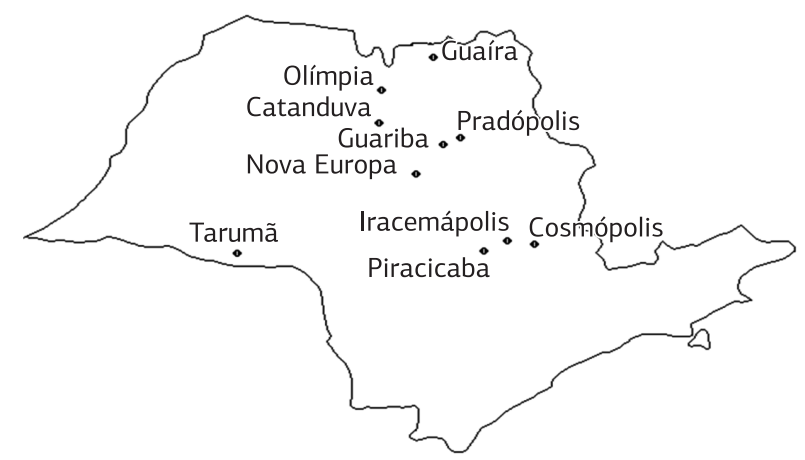

Figura 1. Distribuição dos locais (municípios) onde foram conduzidos os experimentos no estado de São Paulo.

Tabela 1. Localização e identificação dos ambientes, usinas parceiras e dados geográficos dos experimentos de competição de clones de cana-de-açúcar série RB97

\begin{tabular}{lcllclc|}
\hline Municípios & Ambientes & \multicolumn{1}{c}{ Usinas } & Latitude (S) & Longitude (W) & Altitude (m) \\
\hline Tarumã & A1 & Nova América & $22^{\circ} 44^{\prime} 48^{\prime \prime}$ & $50^{\circ} 34^{\prime} 38^{\prime \prime}$ & 509 \\
\hline Nova Europa & A2 & Santa Fé & $21^{\circ} 47^{\prime} 42^{\prime \prime}$ & $48^{\circ} 33^{\prime} 39^{\prime \prime}$ & 490 \\
\hline Pradópolis & A3 & São Martinho & $21^{\circ} 21^{\prime} 34^{\prime \prime}$ & $48^{\circ} 03^{\prime} 56^{\prime \prime}$ & 538 \\
\hline Guariba & A4 & Bonfim & $21^{\circ} 21^{\prime} 36^{\prime \prime}$ & $48^{\circ} 13^{\prime} 42^{\prime \prime}$ & 618 \\
\hline Olímpia & A5 & Cruz Alta & $20^{\circ} 44^{\prime} 14^{\prime \prime}$ & $48^{\circ} 54^{\prime} 53^{\prime \prime}$ & 506 \\
\hline Catanduva & A6 & Cerradinho & $21^{\circ} 08^{\prime} 16^{\prime \prime}$ & $48^{\circ} 58^{\prime} 22^{\prime \prime}$ & 503 \\
\hline Iracemápolis & A7 & Iracema & $22^{\circ} 34^{\prime} 50^{\prime \prime}$ & $47^{\circ} 31^{\prime} 07^{\prime \prime}$ & 608 \\
\hline Guaíra & A8 & Colorado & $20^{\circ} 19^{\prime} 06^{\prime \prime}$ & $48^{\circ} 18^{\prime} 38^{\prime \prime}$ & 517 \\
\hline Cosmópolis & A9 & Ester & $22^{\circ} 38^{\prime} 45^{\prime \prime}$ & $47^{\circ} 11^{\prime} 46^{\prime \prime}$ & 652 & 528 \\
\hline Piracicaba & A10 & Costa Pinto & $22^{\circ} 43^{\prime} 30^{\prime \prime}$ & $47^{\circ} 38^{\prime} 56^{\prime \prime}$ & & 528 \\
\hline
\end{tabular}


cultivados no estado de São Paulo, ocupando o primeiro e segundo lugar, respectivamente, no ordenamento geral do censo 2010 (Chapola et al., 2011).

O plantio foi realizado entre março e abril de 2007. O primeiro corte (cana-planta) foi feito entre julho e agosto de 2008 e o segundo corte (cana-soca), em agosto de 2009. Neste trabalho foram utilizados os resultados de cana-soca. O delineamento experimental utilizado foi em blocos ao acaso com três repetições, com parcelas constituídas de cinco linhas de dez metros, com espaçamento de $1,5 \mathrm{~m}$ entre linhas, totalizando uma área de $75 \mathrm{~m}^{2}$ para cada parcela. Procedeu-se à colheita total das parcelas, obtendo-se a massa de colmos por parcela, que foi transformada para toneladas de colmos por ha $(\mathrm{TCH})$ para as análises estatísticas.

Após a realização das análises de variâncias individuais, foi realizada a análise conjunta, considerando o valor menor que sete para a razáo entre o maior e menor quadrado médio residual como indicativo de homogeneidade dos erros experimentais (Pimentel-Gomes e Garcia, 2002).

Para a análise de adaptabilidade e estabilidade pela regressão bissegmentada (CRUz et al., 1989) foi utilizado o programa GENES (CRUz, 1997), adotando-se o modelo estatístico: $Y_{i j}=b_{0 i}+b_{1 \mathrm{i}} I_{j}+b_{2 \mathrm{i}} T\left(I_{j}\right)+\delta_{i j}+\varepsilon_{i j}$, em que: $Y_{i j}$ é a média do clone $i(i=1,2, \ldots, c)$ no ambiente $j(j=1,2, \ldots, a) ; b_{0 i}$ é a média geral do clone $i$ para todos os ambientes; $b_{1 \mathrm{i}}$ é o coeficiente de regressão linear associado a ambientes desfavoráveis; $b_{1 i}+b_{2 i}$ é o coeficiente de regressão linear associado a ambientes favoráveis; $I_{j}=\left(\frac{Y_{j}}{c}\right)-\left(\frac{Y_{.}}{a c}\right)$ é o índice ambiental, sendo $c$ o número de clones e $a$, o número de ambientes; $\delta_{i j}$ é o desvio da regressão linear; $\varepsilon_{i j}$ é o erro médio associado à média. Para índices $I_{j}$ menores que zero (ambientes desfavoráveis), $T\left(I_{j}\right)=0$, e para $I_{j}$ positivos, $T\left(I_{j}\right)=I_{-} I_{+}$, sendo $I_{+}$a média dos índices positivos.

A análise AMMI (Zobel et al., 1988) combina em um único modelo componentes aditivos para os efeitos principais de genótipos $\left(g_{i}\right)$ e de ambientes $\left(a_{j}\right)$ e componentes multiplicativos para os efeitos da interação $\left(g a_{i j}\right)$ (DuARTE e VenCOVSKY, 1999).

No modelo proposto, além dos termos convencionais de um modelo de análise conjunta de variância, como média geral, efeito de genótipos, efeito de ambientes e erro experimental, conforme descrevem DuARTE e Vencovsky (1999), os demais termos resultam da análise de componentes principais aplicadas à matriz de interaçôes:

$G A(g a)=\left[(\widehat{g} \widehat{a})_{i j}\right]$, sendo $(\widehat{g a})_{i j}=Y_{i j}-\bar{Y}_{i .}-\bar{Y}_{. j}+\bar{Y}_{.}$

O modelo adotado é: $Y_{i j}=\mu+g_{i}+a_{j}+\sum_{k-1}^{n} \lambda_{k} \gamma_{i k} \alpha_{j k}+\rho_{i j}+\bar{\varepsilon}_{i j}$, em que: $Y_{i j}$ é a resposta média do genótipo $i$ no ambiente $j$; $\mu$ é a média geral das respostas; $g_{i}$ é o efeito fixo do genótipo $i(i=1,2, \ldots, g) ; a_{j}$ é o efeito fixo do ambiente $j(j=1$, $2, \ldots, a) ; \lambda_{k}$ é o k-ésimo valor singular de $G A$ (escalar); $\gamma_{i k}$ é o elemento correspondente ao i-ésimo genótipo no vetor singular $g k$ (vetor singular coluna); $\alpha_{j k}$ é o elemento correspondente ao j-ésimo ambiente no vetor $a k$ (vetor singular linha); $\rho_{i j}$ é o resíduo da análise de componentes principais (ACP) presente na $S Q$ da interação $G \times A$ (porção ruído); $\bar{\varepsilon}_{i j}$ é o erro experimental médio, para o qual assumiu-se distribuição independente; $\mathrm{k}$ é o índice que se refere aos eixos principais da ACP aplicada à matriz $G A(k=1,2, \ldots, p)$, sendo $p$ o posto da matriz $G A$, com mínimo entre $(g-1)$ e $(a-1)$; $n$ é o número de eixos ou componentes principais selecionados para descrever o padrão da interação $\mathrm{G} \times \mathrm{A}$.

A interpretação da estabilidade no gráfico biplot AMMI foi realizada a partir da distância dos pontos representativos dos genótipos e ambientes ao escore zero. Assim, os pontos que pouco contribuem para a interação apresentam menor distância, indicando maior estabilidade ( $\mathrm{GAUCH}, 1988$; Pacheco et al., 2005). Para a realização dessa análise utilizou-se o software estatístico R versão 2.15.1, pacote agricolae.

\section{RESULTADOS E DISCUSSÃO}

As análises das variâncias individuais permitiram observar que não houve diferenças significativas entre os genótipos apenas nos ambientes Guariba e Piracicaba. Os coeficientes de variação oscilaram entre $5,0 \%$ e $14,2 \%$, com valor médio de $9,7 \%$, evidenciando boa precisão dos ensaios (Pimentel-Gomes, 1990). As TCH para os ambientes variaram de 91,9 $\mathrm{t} \mathrm{ha}^{-1}$ (Olímpia) a 163,6 $\mathrm{t} \mathrm{ha}^{-1}$ (Catanduva), com média geral de $120,9 \mathrm{t} \mathrm{ha}^{-1}$. Os clones com maior e menor estimativas de produtividade, na média dos locais, foram RB975201 e RB975270, com 132,5 t ha ${ }^{-1}$ e 113,5 t ha ${ }^{-1}$, respectivamente.

$\mathrm{Na}$ análise de variância conjunta, constatou-se que houve diferença entre os genótipos, entre os ambientes, e significância para a interação $G \times A$ (Tabela 2). A significância da interação $\mathrm{G} \times \mathrm{A}$ indica que os genótipos apresentaram um comportamento diferencial para $\mathrm{TCH}$ nos ambientes estudados, justificando a aplicação das análises de adaptabilidade e estabilidade.

Tabela 2. Análise de variância conjunta para os 12 clones de cana-de-açúcar avaliados nos dez ambientes

\begin{tabular}{lcc} 
Fontes de variação & G.L. & Q.M. \\
\hline Blocos/ambientes & 20 & 429,74 \\
Clones & 11 & $1.166,48^{* *}$ \\
Ambientes & 9 & $17.986,69^{* *}$ \\
Clones x ambientes & 99 & $543,74^{* *}$ \\
Resíduo médio & 220 & 138,88 \\
Média & - & 120,87 \\
C.V. $(\%)$ & - & 9,75 \\
\hline ** Significativo a 1\% de probabilidade pelo teste F. &
\end{tabular}




\section{Método de regressão bissegmentada (CRUz et al., 1989)}

Os ambientes Olímpia, Tarumá, Cosmópolis, Pradópolis, Guariba e Piracicaba foram classificados como desfavoráveis e os ambientes Nova Europa, Iracemápolis, Guaíra e Catanduva como favoráveis, em ordem crescente pela classificação do índice ambiental $\left(I_{j}\right)$ (Tabela 3). Os rendimentos médios experimentais de cada município estão bem acima dos rendimentos médios de lavoura comercial, considerando todos os cortes, no ano de 2011 (IвGE, 2011), o que se explica pelas condiçôes experimentais e condição ambiental específica do ano de condução desses experimentos. A classificação em favorável ou desfavorável, de acordo como o método aplicado, leva em conta todo o conjunto de fatores ambientais que influenciam os genótipos, não sendo possível destacar um ou outro. Mesmo assim, essa classificação coincidiu em 70\% com a mesma classificação feita com base no rendimento médio da lavoura em 2011 (Tabela 3).

Cruz et al. (2004) classificaram como genótipo ideal aquele que apresenta alta produtividade (alto $\left.b_{0}\right)$, seja pouco responsivo em ambientes desfavoráveis $\left(b_{1}<1\right)$, responsivo em ambientes favoráveis $\left(b_{1}+b_{2}>1\right)$, seja estável (variância dos desvios da regressão não significativos). No conjunto de materiais estudados, tal genótipo não foi identificado (Tabela 4). A ausência de genótipo ideal pelo método de Cruz et al. (1989) coincide com outros trabalhos em diferentes culturas (LORENCETTI et al., 2004; AlBRECHT et al., 2007; Garbuglio et al., 2007).

A testemunha RB867515 apresentou a segunda maior produtividade e alta estabilidade, com melhor resposta nos ambientes desfavoráveis, apesar de não significativa (Tabela 4), mas que confere com as recomendaçôes agronômicas e o comportamento desse material em áreas comerciais. Os

Tabela 3. Valores médios em toneladas de colmos por ha $(\mathrm{TCH})$ de cana-de-açúcar, respectivos índices ambientais $(I j$ e $T(I j))$, em ordem crescente pela classificação do índice ambiental ( $I j)$, conforme o método de Cruz et al. (1989), e valores médios reais $\left(\mathrm{t}\right.$ ha $\left.{ }^{-1}\right)$ da lavoura no ano de 2011 (IвGE, 2011)

\begin{tabular}{|cllcccc|}
\hline Ambientes & Municípios & TCH & lj & T(lj) & Tipo & Médias reais 2011 \\
\hline A5 & Olímpia & 91,91 & $-28,962$ & 0,000 & Desfavorável & 75,0 \\
\hline A1 & Tarumã & 101,30 & $-19,576$ & 0,000 & Desfavorável & 79,9 \\
\hline A9 & Cosmópolis & 108,05 & $-12,821$ & 0,000 & Desfavorável & 85,0 \\
\hline A3 & Pradópolis & 109,18 & $-11,693$ & 0,000 & Desfavorável & 79,0 \\
\hline A4 & Guariba & 111,23 & $-9,645$ & 0,000 & Desfavorável & 85,0 \\
\hline A10 & Piracicaba & 117,22 & $-3,654$ & 0,000 & Desfavorável & 82,0 \\
\hline A2 & Nova Europa & 124,34 & 3,466 & $-18,122$ & Favorável & 94,2 \\
\hline A7 & Iracemápolis & 130,37 & 9,494 & $-12,094$ & Favorável & 85,0 \\
\hline A8 & Guaíra & 151,58 & 30,702 & 9,115 & Favorável & 90,0 \\
\hline A6 & Catanduva & 163,56 & 42,689 & 21,102 & Favorável & 80,0 \\
\hline Ambientes favoráveis & 142,46 & & & & & 90,0 \\
\hline Ambientes desfavoráveis & 106,48 & & & & 87,3 \\
\hline
\end{tabular}

Tabela 4. Médias gerais $\left(b_{0}\right)$, médias dos ambientes favoráveis $(\mathrm{F})$, médias dos ambientes desfavoráveis (D), coeficiente de regressão para ambientes desfavoráveis $\left(b_{1}\right)$, coeficientes de regressão para ambientes favoráveis $\left(b_{1}+b_{2}\right)$, quadrado médio dos desvios da regressão (QMD) e coeficientes de determinação $\left(\mathrm{R}^{2}\right)$, estimados segundo a metodologia de CRUZ et al. (1989), para 12 clones de cana-de-açúcar avaliados em dez ambientes no estado de São Paulo

\begin{tabular}{|cccccccc|}
\hline Clones & $\mathbf{b}_{\mathbf{0}}$ & $\mathbf{F}$ & $\mathbf{D}$ & $\mathbf{b}_{1}$ & $\mathbf{b}_{\mathbf{1}}+\mathbf{b}_{\mathbf{2}}$ & $\mathbf{Q M D}^{*}$ & $\mathbf{R}^{\mathbf{2}}$ (\%) \\
\hline RB975033 & 115,2 & 132,2 & 103,9 & 0,793 & $0,458^{*}$ & 118,04 & 89,74 \\
\hline RB975039 & 125,3 & 146,0 & 111,6 & 0,901 & $0,202^{* *}$ & $1.459,35^{* *}$ & 45,81 \\
\hline RB975086 & 113,8 & 132,4 & 101,3 & 0,866 & 1,294 & $597,25^{* *}$ & 75,52 \\
\hline RB975157 & 125,5 & 143,7 & 113,3 & 0,917 & 0,856 & 214,52 & 88,01 \\
\hline RB975162 & 121,2 & 144,9 & 105,4 & 1,067 & 1,224 & $297,94^{*}$ & 88,74 \\
\hline RB975184 & 119,8 & 147,2 & 101,6 & $1,337^{* *}$ & 0,902 & $391,89^{* *}$ & 88,54 \\
\hline RB975201 & 132,5 & 162,7 & 112,4 & $1,305^{* *}$ & 0,916 & $646,19^{* *}$ & 81,82 \\
\hline RB975242 & 124,2 & 144,1 & 110,8 & 0,889 & $0,123^{* *}$ & 52,44 & 95,78 \\
\hline RB975270 & 113,7 & 132,7 & 101,1 & 0,822 & $2,269^{* *}$ & 244,01 & 92,96 \\
\hline RB975932 & 115,9 & 135,9 & 102,6 & 0,902 & 0,703 & 221,80 & 86,58 \\
\hline RB867515 & 128,0 & 144,2 & 117,2 & 0,813 & 1,250 & 274,55 & 85,82 \\
\hline SP81-3250 & 115,4 & 143,7 & 96,5 & $1,387^{* *}$ & $1,805^{* *}$ & $543,45^{* *}$ & 88,73 \\
\hline Médias & 120,9 & 142,5 & 106,5 & - & - & - & - \\
\hline
\end{tabular}

*, ** - Significativo a $5 \%$ e $1 \%$ de probabilidade pelo teste $\mathrm{t}\left(b_{1}, b_{1}+b_{2}=1\right)$ e pelo teste $\mathrm{F}(\mathrm{QMD}=0)$, respectivamente 
resultados da testemunha SP81-3250 também combinam com suas recomendaçóes e seu desempenho, apresentando melhor resposta nos ambientes favoráveis. A sua produtividade foi intermediária e com baixa estabilidade, provavelmente devido ao maior número de ambientes desfavoráveis (Tabela 3), onde seu desempenho é irregular. Na Figura 2a é possível observar o comportamento distinto entre as testemunhas, confirmando as recomendaçóes da RB867515, que deve ser alocada nos ambientes desfavoráveis, e da SP81-3250, nos favoráveis.

Os clones RB975157, RB975242 e RB975932 apresentaram produtividade superior à testemunha SP81-3250 e alta estabilidade (quadrado médio dos desvios da regressão não significativos), com $\mathrm{R}^{2}$ de $88,0 \%, 95,8 \%$ e $86,6 \%$,
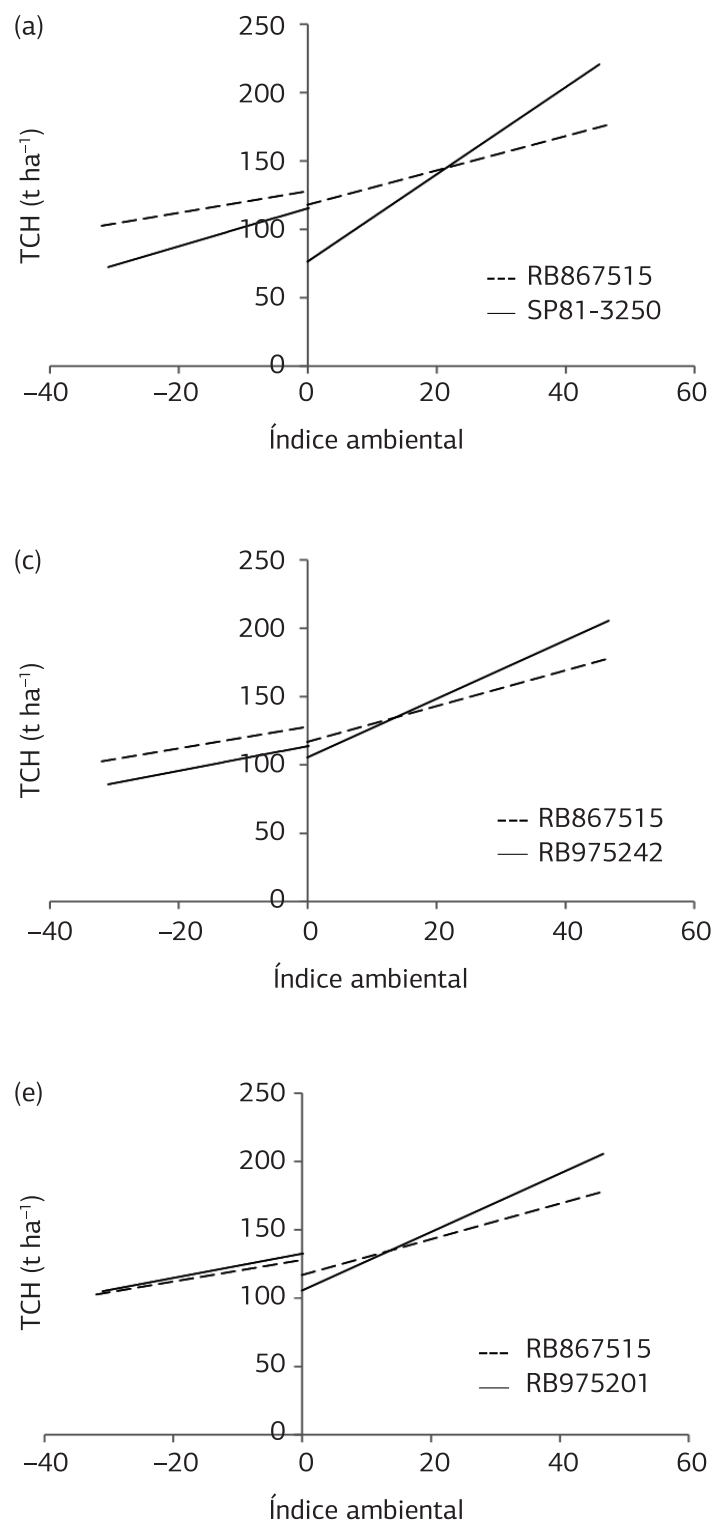

respectivamente. Pelos parâmetros de adaptabilidade, esses clones, embora náo ideais $\left(b_{1}<1\right)$, estáo entre aqueles que apresentaram menor resposta nos ambientes desfavoráveis, com $b_{1}$ estatisticamente igual a unidade, assim como a testemunha RB867515, indicando possíveis genótipos para ambientes mais pobres (Tabela 4; Figura 2b-d).

O clone RB975201 apresentou a maior produtividade no grupo de genótipos estudados. Entretanto, o seu padrão de resposta nos ambientes desfavoráveis foi acima de um $\left(b_{1}>1\right)$ e, nos favoráveis, próximo de um, náo significativo, indicando adaptabilidade específica a esses ambientes, além de significância para o quadrado médio dos desvios, indicando instabilidade (Tabela 4; Figura 2e). Segundo Garbuglio et al. (2007), uma crítica que se pode fazer ao
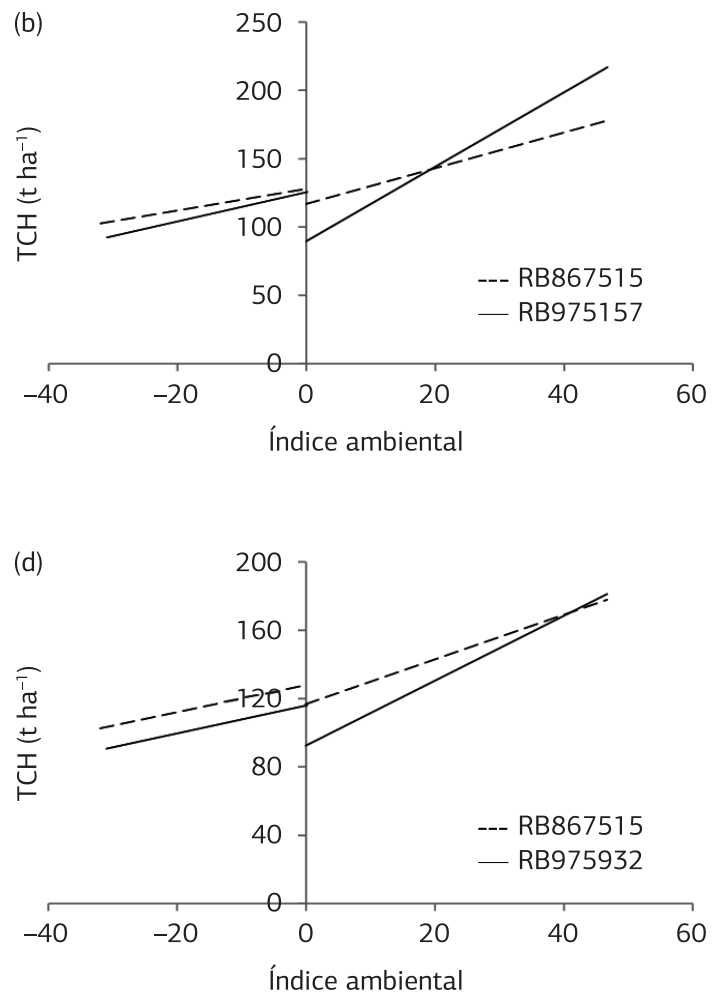

Figura 2. Comportamento das testemunhas de cana-de-açúcar RB867515 e SP81-3250 (a), dos clones RB975157 (b), RB975242 (c), RB975932 (d) e RB975201 (e) em relação à testemunha RB867515 pelo método de regressáo bissegmentada em dez locais do estado de São Paulo para o caráter TCH. 
método de Cruz et al. (1989) refere-se à exigência de o genótipo ser pouco responsivo em ambientes desfavoráveis. Em termos numéricos, esse cuidado é para prevenir que a reta da equação de regressão não atinja pontos inferiores (à zero) em ambientes mais pobres se ela tiver uma inclinaçấo $b_{1} \geq 1$. Mas se $b_{0}$ está entre as mais elevadas, o genótipo é valioso e, nesse caso, o método pouco contribui para entender a falta de resposta à melhoria dos ambientes favoráveis, bem como a magnitude e a significância dos desvios da regressão que causam receio quanto à estabilidade de produção.

Os clones RB975162 e RB975039, apesar de elevada produtividade, apresentaram baixa estabilidade, porém podem ser recomendados para ambientes específicos. O inverso ocorreu com os clones RB975033 e RB975270, com ótima estabilidade porém com baixa produtividade. Ressalte-se que o clone RB975270 foi o que apresentou a maior responsividade para os ambientes favoráveis, superior à testemunha SP81-3250, com coeficiente de regressão $b_{1}+b_{2}=2,3$ contra 1,8 , indicando elevada exigência desse material em ambiente. RB975086 e RB975184 apresentaram-se instáveis e com produtividades baixas.

\section{Método de análise AMMI (ZoBeL et al., 1988)}

Pela análise AMMI, a soma dos quadrados da interação $G \times A$ foi decomposta em dez eixos de componentes principais, chamados de IPCA (Interaction Principal Component Axis).
No entanto, os cinco primeiros eixos foram significativos a 1\% de significância pelo teste F de Gollob (1968). O primeiro eixo da interação capturou $45,2 \%$, o segundo, $19,1 \%$ (64,3\% nos dois primeiros eixos) e o terceiro eixo, $11,7 \%$, totalizando $76,0 \%$ da soma dos quadrados da interação $\mathrm{G} \times \mathrm{A}$. Esse valor dos dois primeiros eixos foi superior ao de Verissimo et al. (2012), com 40,5\%, também para TCH. Nesses primeiros eixos, a maior parte da interaçáo corresponde à porção "padrão"; o restante corresponde à porção "ruído".

Nos primeiros eixos há maior captaçáo da porcentagem de "padrão", que diminui nos eixos subsequentes. Conforme eleva-se o número de eixos selecionados, aumenta-se a porcentagem de "ruído", reduzindo-se o poder de predição da análise (Guerra et al., 2009; Oliveira et al., 2003). Assim, a interpretaçáo gráfica foi realizada considerando-se apenas os biplots AMMI1 (IPCA1 × TCH) e AMMI2 (IPCA1 × IPCA2). No AMMI1 (Figura 3), a abscissa representa os efeitos principais (médias de genótipos) e a ordenada representa o primeiro eixo de interação (IPCA1). Assim, genótipos com valores de IPCA1 próximos de zero sáo considerados de alta estabilidade nos ambientes de teste. Portanto os clones RB975932 (C10), RB975162 (C5), RB975157 (C4) e RB975033 (C1) apresentaram alta estabilidade fenotípica por estarem próximos da linha do eixo IPCA1. Entretanto, o clone RB975033 apresentou baixa produtividade, abaixo das testemunhas. Os clones RB975201 (C7) e RB975242 (C8) apresentaram estabilidade intermediária e adaptabilidade específica com o ambiente Iracemápolis (A7).

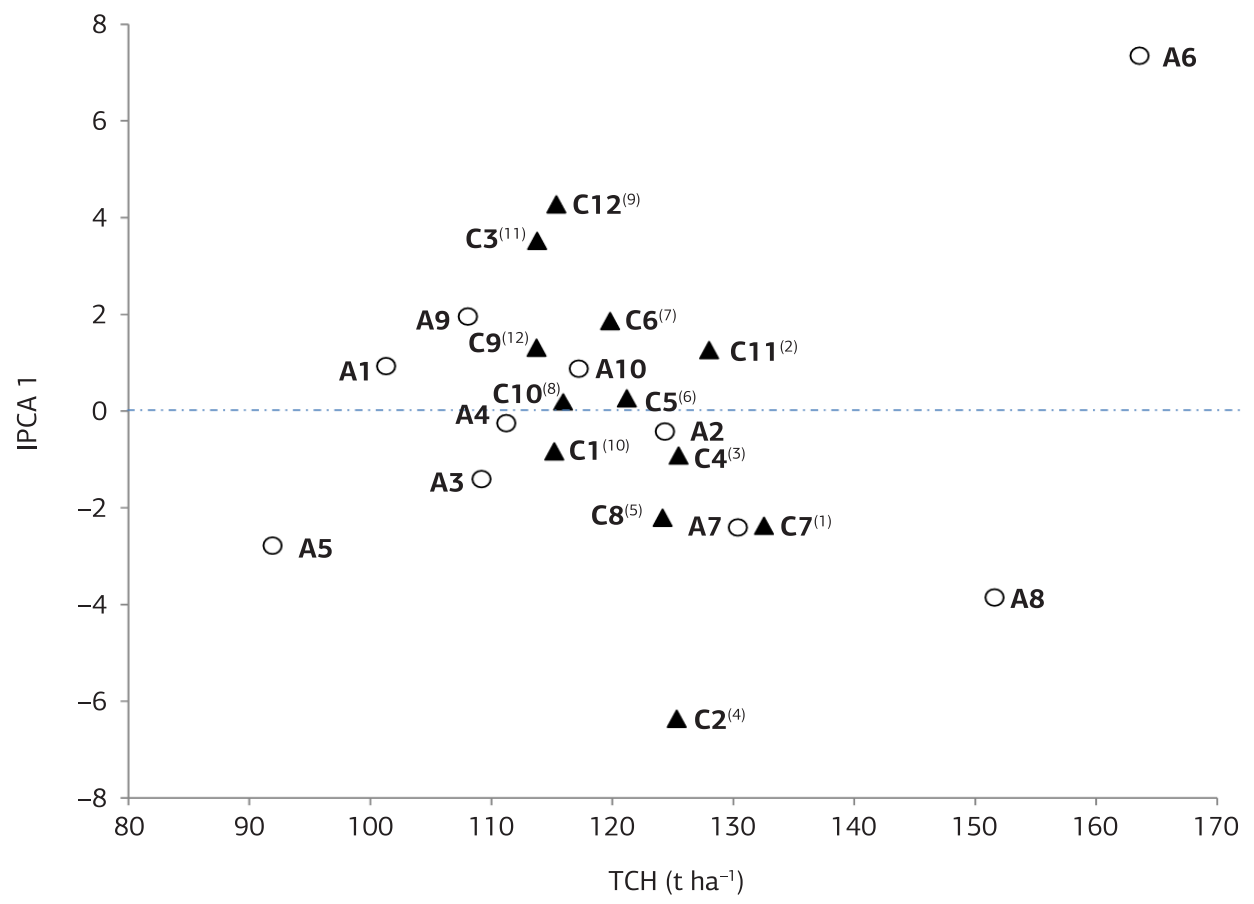

Figura 3. Biplot AMMI1 para TCH em 12 clones de cana-de-açúcar $(\mathrm{C} 1=\mathrm{RB} 975033, \mathrm{C} 2=\mathrm{RB} 975039, \mathrm{C} 3=\mathrm{RB} 975086, \mathrm{C} 4=\mathrm{RB} 975157$, $\mathrm{C} 5=\mathrm{RB} 975162$, C6 = RB975184, C7 = RB975201, C8 = RB975242, C9 = RB975270, C10 = RB975932, C11 = RB867515 e C12 = SP813250) e dez ambientes (A1 = Tarumá, A2 = Nova Europa, A3 = Pradópolis, A4 = Guariba, A5 = Olímpia, A6 = Catanduva, A7 = Iracemápolis, A8 = Guaíra, A9 = Cosmópolis e A10 = Piracicaba); o expoente em C indica a posição do clone na lista de médias em ordem decrescente. 


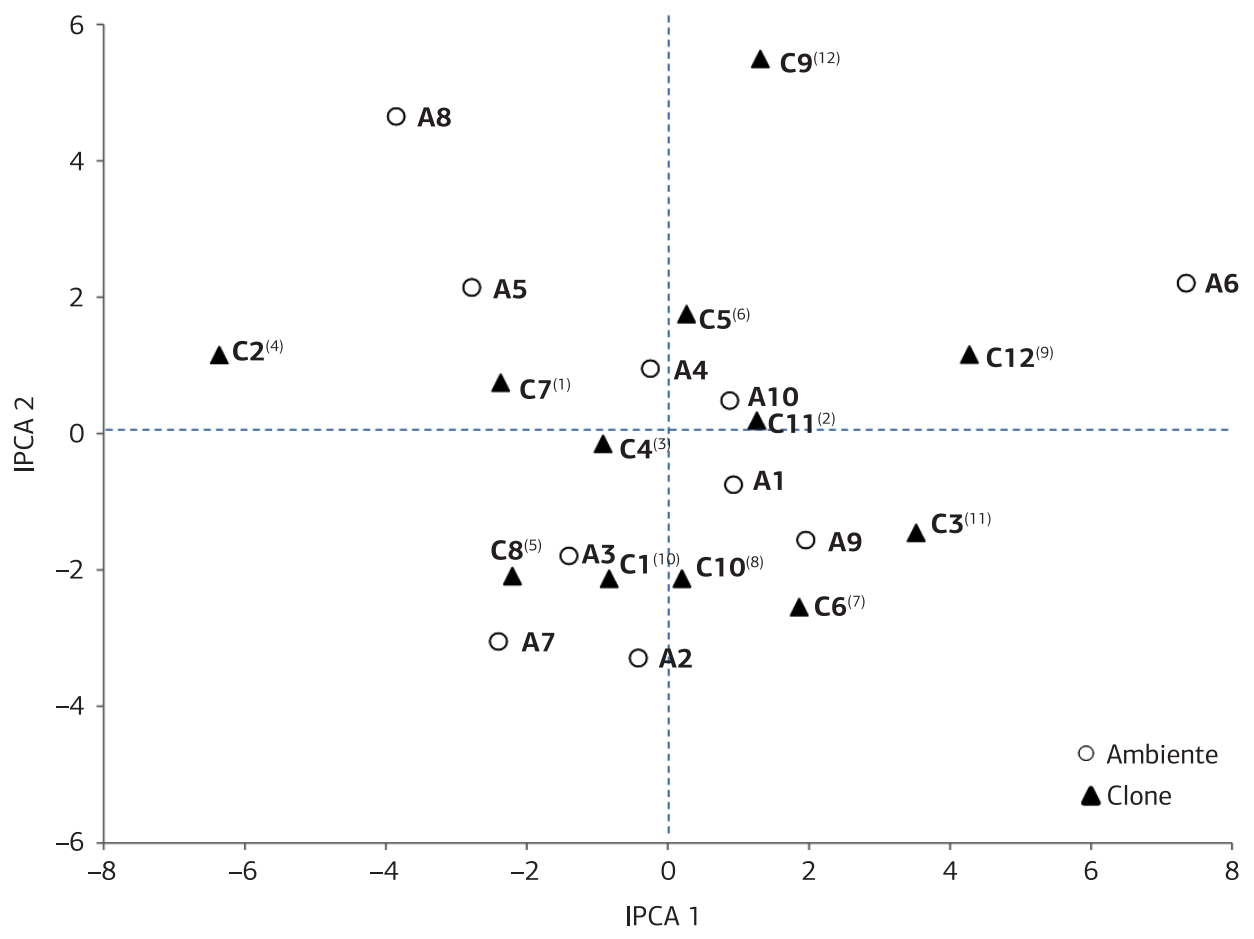

Figura 4. Biplot AMMI2 para dados de TCH em 12 clones de cana-de-açúcar $(\mathrm{C} 1=\mathrm{RB} 975033, \mathrm{C} 2=\mathrm{RB} 975039, \mathrm{C} 3=\mathrm{RB} 975086, \mathrm{C} 4=$ RB975157, C5 = RB975162, C6 = RB975184, C7 = RB975201, C8 = RB975242, C9 = RB975270, C10 = RB975932, C11 = RB867515 e C12 = SP81-3250) e dez ambientes (A1 = Tarumã, A2 = Nova Europa, A3 = Pradópolis, A4 = Guariba, A5 = Olímpia, A6 = Catanduva, A7 = Iracemápolis, A8 = Guaíra, A9 = Cosmópolis e A10 = Piracicaba); o expoente em C indica a posiçáo do clone na lista de médias em ordem decrescente.

Para o gráfico biplot AMMI 2 (Figura 4), os genótipos próximos da origem dos eixos sáo mais estáveis do que aqueles mais afastados, pois contribuíram pouco para a interação. Combinaçóes de genótipos e ambientes com escores IPCA de mesmo sinal têm interações específicas positivas, e combinaçôes de sinais opostos apresentam interaçôes específicas negativas (CHAVEs, 2001). Nesse caso, a alta estabilidade foi confirmada para o clone RB975157 (C4), juntamente com a testemunha RB867515 (C11). Os clones RB975201 (C7) e RB975162 (C5) também apresentaram boa estabilidade no AMMI2. O clone RB975242 (C8) apresentou adaptabilidade específica com os ambientes Pradópolis (A3) e Iracemápolis (A7).

\section{Comparação dos resultados entre os métodos}

Os resultados da análise AMMI condizem com o modelo bissegmentado para os clones RB975157 (C4, AMMI1 e AMMI2) e RB975932 (C10, AMMI1), além da testemunha RB867515 (C11, AMMI2), evidenciando elevada estabilidade. Os métodos também são complementares, sendo que o clone RB975162 (C5), apesar de elevada produtividade, apresentou instabilidade e coeficientes de adaptabilidade não satisfatórios no modelo bissegmentado, mas alta estabilidade com adaptabilidade específica para os ambientes Piracicaba
(A10) e Nova Europa (A2), no AMMI1, e para Guariba (A4), no AMMI2. O clone RB975201 (C7), com maior produtividade entre os materiais estudados, também apresentou instabilidade no modelo bissegmentado, mas, no AMMI2, que captou mais de $64 \%$ da interação, apresentou boa estabilidade, com adaptabilidade específica para os ambientes Iracemápolis (A7) e Guariba (A4), nos biplots AMMI 1 e 2, respectivamente. Essa complementação entre os métodos é interessante de ser considerada na indicação dos melhores clones, permitindo explorar também os efeitos positivos da interação, não descartando genótipos considerados instáveis mas que apresentam adaptabilidade restrita (DUARTE e Vencovsky, 1999).

\section{Zoneamento agronômico pelo método AMMI}

A análise AMMI proporcionou a observação de ambientes similares e mais estáveis, principalmente no biplot AMMI2. Nos escores de IPCA semelhantes, os ambientes são considerados similares. Ambientes estáveis são aqueles onde o ordenamento dos genótipos apresenta maior consistência e confiabilidade em relaçáo à média dos ambientes. Nesses ambientes, genótipos com adaptabilidade geral tendem a se destacar e podem ser selecionados com maior segurança (Duarte e Vencovsky, 1999; Gauch, 1996; Guerra et al., 2009; Veríssimo et al., 2012). 
Os ambientes que menos contribuíram para a interação foram Tarumã (A1), Guariba (A4) e Piracicaba (A10) (Figura 4). Porém, Guariba e Piracicaba não discriminaram significativamente os genótipos na análise individual. Portanto, Tarumá pode ser considerado o mais estável e onde a discriminação dos genótipos foi mais confiável em relação à média dos ambientes testados.

\section{CONCLUSÃO}

Nenhum dos genótipos avaliados apresenta os parâmetros ideais, como preconizado pelo método da regressão bissegmentada. Os clones mais promissores em termos de estabilidade e adaptabilidade geral são RB975201, RB975157, RB975932 e RB975162. O clone RB975242 apresenta alta produtividade, porém com adaptabilidade específica aos ambientes Iracemápolis e Pradópolis. O ambiente Tarumá apresenta maior estabilidade e capacidade de discriminaçáo entre os genótipos, o que permite um ordenamento mais confiável em relação à média geral dos ambientes testados.

\section{REFERÊNCIAS}

ALBRECHT, J.C.; VIEIRA, E.A.; SILVA, M.S.; ANDRADE, J.M.V.; SCHEEREN, P.L.; TRINDADE, M.G.; SOARES SOBRINHO, J.; SOUSA, C.N.A.; REIS, W.P.; RIBEIRO JÚNIOR, W.Q.; FRONZA, V.; CARGNIN, A.; YAMANAKA, C.H. Adaptabilidade e estabilidade de genótipos de trigo irrigado no Cerrado do Brasil Central. Pesquisa Agropecuária Brasileira, v.42, p.1727-1734, 2007. http://dx.doi. org/10.1590/S0100-204X2007001200009

BORÉM, A.; MIRANDA, G.V. Melhoramento de plantas. 5.ed. Viçosa: UFV, 2005. 525p.

CHAPOLA, R.G.; HOFFMANN, H.P.; BASSINELLO, A.I.; FERNANDES JUNIOR, A.R.; VIEIRA M.A.S.; SCHIAVINATO, S.R. Censo varietal 2010 de cana-de-açúcar nos Estados de São Paulo e Mato Grosso do Sul. STAB, v.29, p.42-45 2011.

CHAVES, L.J. Interação de genótipos com ambientes. In: NASS, L.L.; VALOIS, A.C.C.; MELO, I.S.; VALADARES-INGLIS, M.C. (Ed.). Recursos genéticos e melhoramento de plantas. Rondonópolis: Fundaçáo MT, 2001. p.673-713.

COMPANHIA NACIONAL DE ABASTECIMENTO - CONAB. Acompanhamento da safra brasileira: cana-de-açúcar safra 2012/2013. Brasília: CONAB, 2012. 18p. Disponível em: <http://www.conab. gov.br>. Acesso em: 03 set. 2012.

CRUZ, C.D. Programa Genes: aplicativo computacional em genética e estatística. Viçosa: UFV, 1997. 442p.

CRUZ, C.D.; REGAZZI, A.J.; CARNEIRO, P.C.S. Modelos biométricos aplicados ao melhoramento genético. Viçosa: UFV, 2004. v.1, 480p.
CRUZ, C.D.; TORRES, R.A.; VENCOVSKY, R. An alternative approach to the stability analysis proposed by Silva and Barreto. Revista Brasileira de Genética, v.12, p.567-580, 1989.

DUARTE, J.B.; VENKOVSKY, R. Interação genótipos x ambientes: uma introdução à análise "AMMI". Ribeirão Preto: FUNPEC, 1999. 60p. (Série Monografias, n.9). Disponível em: <http://www.agro.ufg. br/uploads/files/Duarte_\&_Vencovsky(1999)-Monografia_SBGAMMI_e_GXE.pdf>. Acesso: em 03 maio 2011.

EBERHART, S.A.; RUSSEL, W.A. Stability parameters for comparing varieties. Crop Science, v.6, p.36-40, 1966.

FINLAY, K.W.; WILKINSON, G.N. The analysis of adaptation in a plant-breeding programme. Australian Journal of Agricultural Research, v.14, p.742-754, 1963. http://dx.doi.org/10.1071/AR9630742

GAUCH, H.G. Model selection and validation for yield trials with interaction. Biometrics, v.44, p.705-715, 1988.

GAUCH, H.G.; ZOBEL, R.W. AMMI analysis of yield trials. In: KANG, M.S.; GAUCH, H.G. (Ed.). Genotype by environment interaction. Boca Raton: CRC Press, 1996. v.4, p.85-122.

GARBUGLIO, D.D.; GERAGE, A.C.; ARAÚJO, P.M.; FONSECA JUNIOR, N.S.; SHIOGA, P.S. Análise de fatores e regressão bissegmentada em estudos de estratificação ambiental e adaptabilidade em milho. Pesquisa Agropecuária Brasileira, v.42, p.183-191, 2007. http://dx.doi.org/10.1590/S0100-204X2007000200006

GOLLOB, H.F. A statistical model which combines features of factor analytic and analysis of variance techniques. Psychometrika, v.33, p.73-115, 1968. http://dx.doi.org/10.1007/BF02289676

GUERRA, E.P.; OLIVEIRA, R.A.; DAROS, E.; ZAMBON, J.L.C.; IDO, O.T.; BESPALHOK FILHO, J.C. Stability and adaptability of early maturing sugarcane clones by AMMI analysis. Crop Breeding and Applied Biotechnology, v.9, p.260-267, 2009.

HOFFMANN, H.P.; FANCELLI, A.L.; MATSUOKA, S. Contribuição de variedades melhoradas de cana-de-açúcar no Estado de Sáo Paulo nos últimos cinquenta anos. STAB, v.18, p.22, 1999.

INSTITUTO BRASILEIRO DE GEOGRAFIA E ESTATÍSTICA - IBGE. Produção agrícola municipal. 2011. Disponível em: <http:// www.sidra.ibge.gov.br/bda/tabela/listabl. asp? $c=99 \& z=t \& o=11>$. Acesso em: 27 jun. 2013.

LORENCETTI, C.; CARVALHO, F.I.F.; MARCHIORO, V.S.; BENIN, G.; OLIVEIRA, A.C.; FLOSS, E.L. Implicaçóes da aplicação de fungicida na adaptabilidade e estabilidade de rendimento de grãos em aveia branca. Ciência Rural, v.34, p.693-700, 2004. http://dx.doi. org/10.1590/S0103-84782004000300007

OLIVEIRA, A.B.; DUARTE, J.B.; PINHEIRO, J.B. Emprego da análise AMMI na avaliação da estabilidade produtiva em soja. Pesquisa Agropecuária Brasileira, v.38, p.357-364, 2003. http:// dx.doi.org/10.1590/S0100-204X2003000300004

OLIVEIRA, J.S. Environmental stratification, adaptability and stability of commercial hybrids of corn for silage utilization in the south of Brazil. Ciência Rural, v.34, p.997-1003, 2004. http://dx.doi. org/10.1590/S0103-84782004000400005 
PACHECO, R.M.; DUARTE, J.B.; VENCOVSKY, R.; PINHEIRO, J.B.; OLIVEIRA, A.B. Use of supplementary genotypes in AMMI analysis. Theoretical and Applied Genetics, v.110, p.812-818, 2005. http://dx.doi.org/10.1007/s00122-004-1822-6

PIMENTEL-GOMES, F.; GARCIA, C.H. Estatística aplicada a experimentos agronômicos e florestais: exposição com exemplos e orientaçōes pra uso de aplicativos. Piracicaba: FEALQ, 2002. 309p.

PIMENTEL-GOMES, F. Curso de estatística experimental. 12.ed. São Paulo: Nobel, 1990. 467p.

SILVA, J.G.C.; BARRETO, J.N. An application of segmented linear regression to the study of genotype $\mathrm{x}$ environment interaction. Biometrics, v.41, p.1093, 1986.
VENCOVSKY, R. Melhoramento genético em vegetais. Ciência e Cultura, v.38, p.1155-1160, 1986.

VENCOVSKY, R.; BARRIGA, P. Genética biométrica no fitomelhoramento. Ribeirão Preto: Sociedade Brasileira de Genética, 1992. 496p.

VERISSIMO, M.A.A.; SILVA, S.D.A.; AIRES, R.F.; DAROS, E.; PANZIERA, W. Adaptabilidade e estabilidade de genótipos precoces de cana-de-açúcar no Rio Grande do Sul. Pesquisa Agropecuária Brasileira, v.47, p.561-568, 2012. http://dx.doi.org/10.1590/S0100204X2012000400012

ZOBEL, R.W.; WRIGHT, M.J.; GAUCH, H.G. Statistical analysis of a yield trial. Agronomy Journal, v.80, p.388-393, 1988. 